East African Medical Journal Vol. 82 No. 3 March 2005

BLOOD DONOR HAEMATOLOGY PARAMETERS IN TWO REGIONS OF KENYA

J. A. Rajab, MBChB, MMed Path, Department of Haematology and Blood Transfusion, W. P. Muchina, BScN, MPh, Department of Nursing Sciences, College of Health Sciences, University of Nairobi P. O. Box 19676, Nairobi, D. A. O. Orinda, MPharm, Dr. Nat. Sciences, MSc, Abbot Diagnostics Division, P. O. Box 51139, Nairobi and C. S. Scott, PhD, FRCPath, Abbott GmbH and Co. KG Diagnostic, Max-plank-Ring2 D-6520 Wiesbaden delkenheim

Request for reprints to: Dr. J. A. Rajab, Department of Haematology and Blood Transfusion, College of Health Sciences, University of Nairobi, P. O. Box 19676, Nairobi, Kenya

\title{
BLOOD DONOR HAEMATOLOGY PARAMETERS IN TWO REGIONS OF KENYA
}

\author{
J. A. RAJAB, W. P. MUCHINA, D. A. O. ORINDA and C. S. SCOTT
}

\begin{abstract}
Objectives: To determine the status of blood donor haematology in two regional sites in Kenya and to assess the potential role of automated haematology in National blood bank process control.

Design: A cross sectional descriptive study.

Setting: Two regional blood banks - Nairobi and its environs (Blood Transfusion Services, Nairobi) and Western Region (National Blood Transfusion Services, Kisumu).

Main outcome measures: Distribution, mean, median, and $95 \%$ percentile ranges of haemoglobin $(\mathrm{Hb})$, red cell parameters (red cell count, haematocrit, MCV, MCH and MCHC), total and differential white blood cell (WBC) counts, and platelet counts in the two donor populations.

Results: A significant number of donations (16.5\% in Kisumu and $3.4 \%$ in Nairobi) showed haemoglobin levels below the recommended National Blood Transfusion Service (NBTS) guideline of $\mathbf{4 2 g}$ /unit. Compared to Kisumu, Nairobi donors had significantly ( $p<0.001$ ) higher $\mathrm{Hb}, \mathrm{MCV}$ and $\mathrm{MCH}$ values while the red blood cell counts and MCHC values were similar $(\mathrm{p}>0.05)$. A low MCV $(<78 f 1)$ was observed in $12.4 \%$ and $3.4 \%$ of Kisumu and Nairobi donors respectively. Both populations showed similar but significant frequencies (Kisumu, 21.3\%; Nairobi, 18.7\%) of mild neutropenia $(<1.5 \mathrm{x}$ $\left.10^{9} / \mathrm{l}\right)$, while eosinophilia $\left(>0.5 \times 10^{9} / \mathrm{l}\right.$ in the tropics the cut off is $\left.>0.6 \times 109\right)$ was more prominent in Kisumu donors $\mathbf{( 1 8 . 8 \%}$ versus $\mathbf{8 . 5 \%})$. Platelet counts were also significantly lower in Kisumu donors, with the prevalence of thrombocytopenia $(<150 \times 109 / 1)$ being considerably higher $(15.9 \%$ versus $3.7 \%)$.

Conclusions: A significant number of Kenyan donors showed abnormal haematology profiles that may indicate underlying pathology. Such abnormalities are not detected by current blood transfusion services screening practices and there may be a need to strengthen donor selection criteria to protect both donors and recipients.
\end{abstract}

\section{INTRODUCTION}

The World Health Assembly and the regional commonwealth ministers of health recommended that their member states develop comprehensive and well co-ordinated blood transfusion services based on voluntary, non-remunerated blood donation (Resolutions WHA28.72 of 1972 and 1989) (1). Safety of the donor and the recipient is of highest priority and all processes and procedures must be followed to ensure this safety.

Blood banks aim at ensuring high quality of blood and blood products from the selection of donor, storage, transport and transfusion to the recipient. Prior to blood collection, donors must pass a medical review including a personal medical history and physical examination. In Kenya, the Ministry of Health policy guidelines on blood transfusion states that a donor's blood pressure, haemoglobin and haematocrit values must also be determined and that a donor must be healthy, between the ages of 16 and 65 years, of at least $50 \mathrm{~kg}$ body weight and have a minimum $12.5 \mathrm{~g} / \mathrm{dL}$ haemoglobin (10mg/dL for autologous donation).

Donor selection strategies are designed to meet the needs of blood transfusion in modern medical practice. Since the purpose of blood transfusion is to treat patients, the medical doctrine of premum non nocere (firstly or, above all else, do no harm) becomes the primary principle in the selection of blood donors (2). It is recommended that a voluntary non-remunerated donor be recruited for low risk blood donation. However this may not always be the case for blood bank services in Kenya, which mainly rely on campaigns for blood donations that are institution and community based. Sheer numbers and time constraints may compromise the rigid application of donor selection criteria, as blood bank personnel may be overwhelmed. Donor haematology profiles are rarely assessed and the less than satisfactory copper sulphate haemoglobin method is often the only parameter screened. 
Several factors including genetics, dietary patterns, sex, age, altitude and geographical location affect haematological parameters (3-5). This study was conducted in two regions in Kenya (Nairobi and Kisumu) with significant differences in altitude, climate, disease prevalence and ethnic origin in order to assess and compare blood donor haematological profiles. This survey represents the largest systematic study of blood donor haematological status in Kenya and was part of a larger study to determine the risk of Transfusion Associated Malaria (TAM). The haematological data obtained for blood donations obtained in this study also provided an opportunity to evaluate the potential utility of automated haematology for donor assessments and blood bank process control in Kenya.

\section{MATERIALS AND METHODS}

Blood donations studied: Study samples included all consecutive donor units received at the regional blood transfusion centers in Nairobi and Kisumu over periods of three months. The only exclusions from this study were units that were identified as 'short donations' or those with measured haemoglobin of $<6.0 \mathrm{~g} / \mathrm{dl}$. A total of 3203 donations were haematologicaly analysed from the two centers; 1718 from Nairobi and 1485 from Kisumu.

Donor screening and selection was carried out according to $\mathrm{MOH}$ policy guidelines. Approximately $95 \%$ of blood donations were venesected geographically outside the blood banks and then transported to the central facilities. For Nairobi the furthest collection site was Kiganjo $(173 \mathrm{~km})$ while for Kisumu the remotest collection site (Bungoma) is approximately $200 \mathrm{~km}$ from the central blood bank. When possible the blood donations were sent to the central facility the same day or, if impractical, stored at the nearest District Hospital Blood Bank prior to transport the following day. Blood donations were collected using two different collection packs (Terumo, Japan; JM2, India) in Kisumu and one type in Nairobi (Terumo). The average blood donations for both sites were $400 \mathrm{ml}$ (acceptable range $350-450 \mathrm{ml}$ ) with the anticoagulant volume being $60 \mathrm{ml}$. The relative proportion of donor blood to anticoagulant in the collected units therefore corresponded to 0.85 .

Haematological analysis: Aliquots of all donations were collected in bar-coded vacutainer tubes, and donation reference numbers and the results of all tests procedures were recorded on spreadsheets in both hard copy and electronic form. Samples were analysed with the Abbott Cell-Dyn CD3200 automated haematology instrument. This analyser is a fully automated system capable of reporting a total blood count (TBC) and five part differential with a throughout of 64 samples per hour. In normal operational mode, two main measurement principles are used. For the determination of haemoglobin concentration photometric light absorption is measured after haemolysis with a cyanide-free reagent. For all other measurements, including cell counting, sizing and leukocyte differentiation, optical analysis with a $633 \mathrm{~mm}$ Helium-Neon laser is used. Throughout the study the quality control and instruments were maintained and calibrated according to the manufacturer's recommendations.

Data inclusion criteria and statistical analysis: Preliminary assessments (data not shown) of individual red cell, white cell and platelet parameters were undertaken in order to determine the effects of prolonged storage (i.e. delay between donation collection and analyser processing). This was necessary to ensure that data were a true reflection of donor haematology status. Biological deterioration was assessed by empirical reference to the Cell-Dyn CD3200 graphical displays of neutrophil integrity, as a change in the morphological characteristics of this leukocyte fraction is a sensitive indicator of biological change $(6,7)$.

For analysis of red cell parameters, all results $(n=3203)$ were considered to be evaluable irrespective of biological deterioration. In contrast, neutrophil and platelet counts were significantly affected by sample ageing and thus, for the purposes of this survey, leukocyte population and platelet parameters were only assessed for the 1394 donations with no evidence of neutrophil deterioration.

Evaluable donations were statistically analysed to determine distribution frequencies (including mean and median) and $95 \%$ percentile ranges (defined as the mean $\pm 2 \mathrm{SD}$ ). These were determined individually for Kisumu and Nairobi, and comparisons between the two donor groups were made using the independent samples t-test.

\section{RESULTS}

Red blood cell parameters: A total of 3203 donor samples from two Kenyan regional blood banks (Nairobi, $\mathrm{n}=1718$; Kisumu, $\mathrm{n}=1485$ ) were analysed. The mean $\mathrm{Hb}$ concentration of $13.18 \mathrm{~g} / \mathrm{dl}$ for Nairobi donors (Figure 1a) was significantly higher $(\mathrm{p}<0.001)$ than Kisumu (12.63g/dl, Figure 1b) although red cell counts in both populations were similar (Table 1). Based on a nominal blood donation volume of $400 \mathrm{ml}$, and applying the Council of Europe (CE) (8) guideline that minimum total haemoglobin content for any donation should be $45 \mathrm{~g}$ then $24.4 \%$ of the Kisumu donations would have failed to meet this requirement compared to $8.7 \%$ of the Nairobi donations.

With regard to RBC mean cell volumes (MCV), there was also a significant difference between donors from Kisumu and Nairobi (Figure 2 and Table 1). In Kisumu, the most common abnormality was microcytosis i.e. $\mathrm{MCV}<77 \mathrm{fl}$ ( $12.4 \%$ of donations), with relatively few donors (1.4\%) having macrocytosis i.e. MCV > 100fl. In contrast, microcytosis was less common in Nairobi donors (3.3\%) while the frequency of macrocytosis, although small $(4.1 \%)$ was noticeably greater.

For the other evaluated red cell parameters, significantly $(\mathrm{p}<0.001)$ lower haematocrit and mean cell haemoglobin $(\mathrm{MCH})$ values were obtained for the Kisumu donor population, almost certainly reflecting their clear tendency to microcytosis, while mean cell haemoglobin concentrations (MCHC) were broadly similar in the two donor groups (Table 1).

White blood cell parameters: Assessment of total and differential population absolute counts were undertaken only for donations that did not show biological deterioration (Nairobi, $\mathrm{n}=402$; Kisumu, $\mathrm{n}=992$ ). Biological deterioration was observed with a much higher proportion of donations in the Nairobi series (76\%) compared to Kisumu (33.2\%) although this largely reflected the longer delay between time of collection and haematological processing. 
Table 1

Statistical analysis and comparisons of red cell parameters for 3203 donated units from two regional blood banks in Kenya

\begin{tabular}{|c|c|c|c|c|c|c|c|}
\hline $\begin{array}{l}\text { Region Group } \\
\text { and Statistics }\end{array}$ & $\begin{array}{l}\text { (n)Haemoglobin } \\
\text { Level }(\mathrm{g} / \mathrm{dL})\end{array}$ & $\begin{array}{l}\text { RBC count } \\
10^{12 / L}\end{array}$ & $\begin{array}{l}\text { Haemoglobin } \\
\text { Level (g/dL) }\end{array}$ & $\begin{array}{c}\text { Haematocrit } \\
(\%)\end{array}$ & $\begin{array}{l}\mathrm{MCV} \\
(\mathrm{fL})\end{array}$ & $\begin{array}{c}\mathrm{MCH} \\
(\mathrm{pg})\end{array}$ & $\begin{array}{c}\mathrm{MCHC} \\
(\mathrm{g} / \mathrm{dl})\end{array}$ \\
\hline \multicolumn{8}{|c|}{ Nairobi $(n=1718)$} \\
\hline Mean \pm SD & $13.18 \pm 1.44$ & $4.52 \pm 1.04$ & $13.18 \pm 1.44$ & $40.68 \pm 3.91$ & $90.43 \pm 6.05$ & $29.28 \pm 2.27$ & $32.37 \pm 1.10$ \\
\hline Median & 13.20 & 4.52 & 13.20 & 41.00 & 90.60 & 29.50 & 32.40 \\
\hline $95 \%$ range & $10.30-16.06$ & $3.48-5.56$ & $10.30-16.06$ & $32.86-48.50$ & $78.33-102.53$ & $24.76-33.80$ & $30.17-34.50$ \\
\hline \multicolumn{8}{|c|}{ Kisumu $(\mathrm{n}=1485)$} \\
\hline Mean $\pm S D$ & $12.63 \pm 2.30$ & $4.56 \pm 0.85$ & $12.63 \pm 2.30$ & $38.88 \pm 7.10$ & $85.65 \pm 7.06$ & $27.86 \pm 2.83$ & $32.49 \pm 1.43$ \\
\hline Median & 12.74 & 4.51 & 12.74 & 38.79 & 86.41 & 28.21 & 32.45 \\
\hline $95 \%$ range $^{\mathrm{a}}$ & $8.03-17.23$ & $2.86-6.43$ & $8.03-17.23$ & $24.68-53.08$ & $71.53-99.77$ & $22.20 \pm 33.52$ & $29.63 \pm 35.30$ \\
\hline Difference & $<0.001$ & ns & $<0.001$ & $<0.001$ & $<0.001$ & $<0.001$ & ns \\
\hline \multicolumn{8}{|c|}{ Combined $(\mathrm{n}=3203)$} \\
\hline Mean $\pm S D$ & $12.92 \pm 1.91$ & $4.54 \pm 0.70$ & $12.92 \pm 1.91$ & $39.84 \pm 5.69$ & $88.21 \pm 7.00$ & $28.62 \pm 2.64$ & $32.43 \pm 1.27$ \\
\hline Median & 13.10 & 4.52 & 13.10 & 40.20 & 88.77 & 29.00 & 32.40 \\
\hline $95 \%$ range & $9.10-16.74$ & $3.14-5.94$ & $9.10-16.74$ & $28.46-51.22$ & $74.22-102.21$ & $23.34-33.90$ & $29.89-34.90$ \\
\hline
\end{tabular}

a $95 \%$ range defined as mean value \pm 2 SD. Differences between Nairobi and Kisumu obtained with independent samples t-test. ns, not significant $(\mathrm{p}>0.05)$

Table 2

Statistical analysis and comparisons of leukocyte and platelet parameters for 1394 donated units from two regional blood banks in Kenya

\begin{tabular}{|c|c|c|c|c|c|c|c|}
\hline $\begin{array}{l}\text { Region Group (n) } \\
\text { and Statistics }\end{array}$ & $\begin{array}{c}\text { Total WBC } \\
\text { count }\end{array}$ & $\begin{array}{l}\text { Neutrophil } \\
\text { count }\end{array}$ & $\begin{array}{l}\text { Lymphocyte } \\
\text { count }\end{array}$ & $\begin{array}{l}\text { Monocyte } \\
\text { count }\end{array}$ & $\begin{array}{l}\text { Eosinophil } \\
\text { count }\end{array}$ & $\begin{array}{l}\text { Basophil } \\
\text { count }\end{array}$ & $\begin{array}{c}\text { Total Platelet } \\
\text { count }\end{array}$ \\
\hline \multicolumn{8}{|l|}{ Nairobi (n=402) } \\
\hline Mean $\pm \mathrm{SD}$ & $5.16 \pm 1.46$ & $2.33 \pm 1.07$ & $2.18 \pm 0.62$ & $0.36 \pm 0.14$ & $0.21 \pm 0.29$ & $0.08 \pm 0.05$ & $291.6 \pm 95.6$ \\
\hline Median & 5.00 & 2.20 & 2.10 & 0.35 & 0.10 & 0.10 & 282.0 \\
\hline $95 \%$ range & $2.24-8.08$ & $0.19-4.47$ & $0.94-3.42$ & $0.08-0.64$ & $0.00-0.80$ & $0.00-0.18$ & $100.4-428.8$ \\
\hline \multicolumn{8}{|l|}{ Kisumu (n=992) } \\
\hline Mean $\pm \mathrm{SD}$ & $4.89 \pm 1.69$ & $2.21 \pm 1.05$ & $1.93 \pm 0.75$ & $0.38 \pm 0.20$ & $0.31 \pm 0.34$ & $0.06 \pm 0.04$ & $220.7 \pm 73.5$ \\
\hline Median & 4.59 & 2.00 & 1.82 & 0.34 & 0.21 & 0.05 & 216.0 \\
\hline $95 \%$ range $^{a}$ & $1.51-8.27$ & $0.11-4.31$ & $0.43-3.43$ & $0.02-0.77$ & $0.00-0.99$ & $0.00-0.14$ & $73.7-367.7$ \\
\hline Difference & 0.01 & ns & $<0.001$ & ns & $<0.001$ & $<0.001$ & $<0.001$ \\
\hline \multicolumn{8}{|l|}{ Combined $(n=1394)$} \\
\hline Mean \pm SD & $4.96 \pm 1.63$ & $2.24 \pm 1.05$ & $2.00 \pm 0.72$ & $0.37 \pm 0.18$ & $0.28 \pm 0.33$ & $0.06 \pm 0.04$ & $241.2 \pm 86.6$ \\
\hline Median & 4.70 & 2.04 & 1.91 & 0.34 & 0.19 & 0.06 & 235.1 \\
\hline $95 \%$ range & $1.70-8.22$ & $0.14-4.34$ & $0.56-3.44$ & $0.01-0.73$ & $0-0.94$ & $0.00-0.14$ & $68.0-414.4$ \\
\hline
\end{tabular}

a $95 \%$ range defined as mean value \pm 2 SD. Differences between Nairobi and Kisumu obtained with independent samples t-test. ns not significant $(\mathrm{p}>0.05)$

Table 3

Frequency of defined haematological abnormalities in Kisumu and Nairobi blood donors

\begin{tabular}{llrr}
\hline Abnormality & Definition & \multicolumn{1}{c}{$\begin{array}{l}\text { Kisumu }(\mathrm{n}=922) \\
\text { No. }(\%)\end{array}$} & $\begin{array}{c}\text { Nairobi }(\mathrm{n}=402) \\
\text { No. }(\%)\end{array}$ \\
\hline Severe Neutropenia & $<0.5 \times 10^{9} / \mathrm{L}$ & $3(0.3)$ & $5(1.2)$ \\
Mild/Moderate Neutropenia & $0.5-1.5 \times 10^{9} / \mathrm{L}$ & $212(21.3)$ & $75(18.7)$ \\
Neutrophilia & $>10.0 \times 10^{9} / \mathrm{L}$ & $2(0.2)$ & $1(0.2)$ \\
Marked Eosinophilia & $>1.0 \times 10^{9} / \mathrm{L}$ & $34(3.4)$ & $6(1.5)$ \\
Mild Eosinophilia & $<0.5 \times 10^{9} / \mathrm{L}$ & $53(15.4)$ & $28(7.0)$ \\
Severe Thrombocytopenia & $<50 \times 10^{9} / \mathrm{L}$ & $153(15.4)$ & $0.0)$ \\
Mild Thrombocytopenia & $50-150 \times 10^{9} / \mathrm{L}$ & $5(0.5)$ & $9(3.7)$ \\
Thrombocytosis & $>450 \times 10^{9} / \mathrm{L}$ & & $9(2.2)$ \\
\hline
\end{tabular}


Examination and comparison of total WBC counts indicated lower $(\mathrm{p}=0.01)$ values in Kisumu, which appeared to be primarily due to, significantly $(\mathrm{p}<0.001)$ lower absolute lymphocyte counts (Table 2). Despite the overall trend for lower lymphocyte counts in the Kisumu donor group, no significant individual donor abnormalities associated with lymphopenia (or lymphocytosis) were observed. Specific review of leukocyte population numbers also revealed a high frequency of neutropenia in both the Kisumu and Nairobi donor populations (Table 3), with a small number of these being severe $\left(<0.5 \times 10^{9} / \mathrm{L}\right)$. In addition, eosinophilia $\left(>0.5 \times 10^{9} / \mathrm{L}\right)$ was more commonly seen in Kisumu donors ( $18.8 \%$ compared to $8.5 \%$ in Nairobi), and this was marked (>1.0 x $\left.10^{9} / \mathrm{L}\right)$ in a significant minority (Table 3 ).

Platelet parameters: Platelet counts in the Kisumu donor population were significantly lower $(p<0.001$; Table 2) than seen in Nairobi. In addition, the distribution of donation platelet counts for the two blood bank sites showed that thrombocytopenia was more likely to be seen in the Kisumu population. While a small proportion $(3.7 \%)$ of donations from Nairobi had mild thrombocytopenia, almost $15 \%$ of the Kisumu donations had reduced platelet counts (Table 3 ).

\section{DISCUSSION}

Kenya National Blood Transfusion Service operational practices requires collection of blood from healthy non-remunerated volunteer donors who are expected to undergo a medical examination and submit to a health questionnaire relevant to blood donation (1). Only individuals who meet certain criteria are recruited, and donors are accorded every opportunity to defer if they feel that their blood may not be safe for transfusion. Haemoglobin is the only required haematological measurement $(12.5 \mathrm{~g} / \mathrm{dl}$ and $10 \mathrm{~g} / \mathrm{dl}$ for autologous donation) in the transfusion guidelines (1) and criteria for other haematological parameters are not stated. However, in this survey of donor haematology a significant number of collected blood units in both Kisumu and Nairobi regions had total haemoglobin levels below the minimum Council of Europe (CE) (8) guideline of $45 \mathrm{~g}$. This implies a flaw in the mechanisms of donor selection and/or efficiency of the current copper sulphate haemoglobin screening method.

The Nairobi and Kisumu regional blood processing centres have similar transfusion services practices but differ significantly with respect to altitude, population composition (ethnic diversity) and disease (especially malaria) prevalence. These factors are important, as they are likely to affect haematological status (9). Most donations are collected as part of institutional campaigns and donor haemoglobin level is assessed with the copper sulphate method. Approximately 95\% of donations are venesected geographically outside the blood bank and transported to the central facility within
6 to 8 hours of collection or, if this is impractical, the following day after overnight storage at an appropriate local facility. In this process, maintenance of blood between 1 and $10^{\circ} \mathrm{C}$ during transport and storage is an important requirement for ensuring the availability of a safe blood supply (10).

In this study, regional variations in haematology profiles associated with nutritional deficiencies and disease prevalence were demonstrated. This is a reflection of the economic status of the populations and accessibility to healthcare. All the red cell indices except red cell count and MCHC showed significant differences between in the two studied donor populations. Nairobi province is at a higher altitude and is a cosmopolitan population, being the industrial and administrative capital of the country. Most donors are of African origin although from diverse ethnic backgrounds. Another important factor that may contribute to the observed differences in the red cell data is the endemicity of malaria in Kisumu region. Nairobi is a presumed malaria-free zone whereas transmission becomes holoendemic during the wet humid season in Kisumu region (11). Additionally, in many rural populations sub-clinical helminthic infections (especially hookworm) are also prevalent. Consequently, the combined effects of chronic malaria and helminthic infections together with nutritional deficiencies (12), are likely to be the main causes of lower haemoglobin levels in the Kisumu donor population. Although there is no defined donation standard for $\mathrm{MCV}$, it is nevertheless a useful parameter for highlighting the existence of potential donor pathology that may otherwise be unrecognised. The microcytosis observed in a significant proportion of the Kisumu donors further supports the interpretation of negative iron balance in this population. Both clinical and sub-clinical iron deficiency constitute one of the most frequently encountered nutritional anaemias and the prevalence of iron-responsive microcytic hypochronic anaemias varies from 9\% - 70\% in different population groups (13). In Kenya iron deficiency anaemia accounts for $7.4 \%$ - 38.6\% of all anaemias (14).

Both donor populations also showed significant frequencies of neutropenia, with a small proportion of these being severe in nature. The relatively low absolute WBC and neutrophil counts, compared to those reported for Caucasians, is similar to previous findings in Kenya (15) and other African populations where dietary, environmental and genetic factors have been implicated (16-19). Eosinophilia was the other commonly observed leukocyte abnormality and was particularly evident in the Kisumu group. This again would be consistent with the higher prevalence of parasitic diseases (notably helminthic) infestations in this region.

The much higher frequency of thrombocytopenia in Kisumu donors (15.9\%) compared to those from Nairobi $(3.7 \%)$ is also in accord with undetected illness, such as sub-clinical malaria, or other environmental factors. 
The low platelet counts for the Kenyan donor groups compared well with those noted for other African populations (18-21). This study has demonstrated limitations in the Kenyan blood collection programme with regards to both the suitability of donors, some of which clearly appear to have abnormal haematology profiles suggestive of significant pathology, and in subsequent process control. Stringent haematological screening that includes determination of full haematological parameters (MCV, MCH, WBC and platelets) rather than haemoglobin alone would almost certainly improve donor safety and product quality for the recipient.

\section{ACKNOWLEDGEMENTS}

Mr. S. M. Muthini, senior medical technologist, Department of Haematology and blood transfusion, Faculty of Medicine University of Nairobi. Ms. M. O. Lugalishi, laboratory technician. Ministry of Health, Kenya. Mr. R. Onyango. Deputy director technical services, Mr. A. O. Ogwang, Laboratory technologist, Regional blood transfusion center, Kisumu, Kenya, The National Blood Transfusion Services (NBTS), Ministry of Health, Kenya. Abbott Gmbh and Co. KG Diagnostika, Phillips Pharmaceuticals and the University of Nairobi.

\section{REFERENCES}

1. Kenya MOH (Ministry of Health). National Guidelines on Blood Transfusion in Kenya 2001.

2. Crook, R. Donor selection strategies for reducing risk of transfusion transmitted infection. Afr. Society Blood Trans. 2004; 7:1-2

3. Hoffmann, R, G. Establishing Quality Control and Normal Ranges in the Clinical Laboratory. Exposition Press Inc. Jericho, N.Y. 1971; 73.

4. Tsagaye, A. T., Messele, T., Tilahun, E. et al. Immunohaematological reference ranges for adult Ethiopians. Clin. Diag. Lab. Immunol. 1999; 6:410-414.

5. John, P., Greer, John F. John, N. L., George, M. R., Frixos, P. and Bertil, G. Wintrobe's Clinical Haematology, Appendix A.
Normal Blood and Bone marrow Values in Humans. Lipincott Williams and Wilkins, Philadelphia, 11th ed. 2004; 2:2697.

6. Paparo, C., Tagini, E., Meda, R., Scott, C. S. and Novaro, O. Improved stability of leukocytes in aged samples; investigation of an alternative anticoagulant strategy in hematology for use in Abbott cell-Dyn 3500 hematology analyser. Euro. J. Lab. Med. 1998; 6:16-23.

7. Erwa, W. Bauer, F. R. Etscmaier, R. Steiner,U. Scott, C. S. and Sedimayr, P. Analysis of aged samples with the Abbott CD 4000 hematology analyzer. Euro. J. Lab. Med. 1998; 6:4-15.

8. Commission Directive 2004/33/EC of March 222004. Annex IV, Chapter 2.

9. Evans, D. M., Frazer, I. H. and Martin, N. G. Genetic and environmental causes of variations in basal levels of blood cells. Twin Res. 1999; 2:250-257

10. WHO. African Society for Blood Transfusion. 2002; 7:1.

11. Ministry of Health. National guidelines for diagnosis, treatment and prevention of malaria for health workers. Nairobi Kenya 1997; 145 -115

12. Kenya Central Bureau of Statistics: Demographic Health Survey. Nairobi, Kenya July 2004.

13. World Health Organization. Control of nutritional anaemia with special reference to iron deficiency. Geneva: WHO Tech Rep 1975; 580.

14. Carter, J. Y., Lema, O. and E. Mukunza. Prevalence of anaemia in western rift valley. East Afr. Med. J. 1999; 76:251-254.

15. Kasili, E. G., Cardwell, C. L. and Taylor, J. R. Leucocyte counts on blood donors in Nairobi. East Afr. Med. J. 1969; 46:676-679.

16. Sahr, F., Hazra, P. K. and Grillo, T. A. White blood cell count in healthy Sierra Leoneans. West Afr. J. Med. 1995; 14:105-107.

17. Bain, B. J. Ethnic and sex differences in the total and differential white cell count and platelet count. J. clin. pathol. 1996; 49:664-666.

18. Sharper, A. G. and Lewis, P. Genetic neutropenia in people of African origin. Lancet 1971; 2:1021-1023.

19. Ezeilo, G. C. Non-genetic neutropenia in Africans. Lancet 1972; 2:1003-1004.

20. Gill, G. V., England, A. and Marshal. C. Low platelet counts in Zambians. Trans. R. Soc. Trop. Med. Hyg. 1979; 73:111-112.

21. Coetzee, M. J., Badenhorst, P. N. de Wet, J. 1. and Joubert, G. Haematological conditions of the san (Bushmen) relocated from Namibia to South Africa. S. Afr. Med. J. 1994; 84:416-420. 